\section{Teoría y praxis de una pastoral salvífica y curativa*}

\author{
María Marcela Mazzini ${ }^{\star *}$
}

RECIBO: 05-05-14- APROBACIÓN: 15-10-14

Resumen: Intenta una aproximación a la psicología pastoral desde la propuesta de Isidor Baumgartner. Al partir de una breve historia de la misma, desarrolla un marco teórico, y hace una opción por el autor de referencia describiendo las ideas principales de su pensamiento y método. El texto culmina con la apropiación del pensamiento de dicho autor, retomando dos puntos fuertes de su planteamiento: la fuerza salvífica que aporta el hecho de unir la propia historia a la del Señor y la capacidad de los símbolos para transformar la experiencia espiritual. Palabras Clave: Psicología pastoral, praxis, Emaús, acompañamiento espiritual, curación.

PARA CITAR ESTE ARTÍCULO:

Mazzini, María Marcela. "Teoría y praxis de una pastoral salvífica y curativa.” Theologica Xaveriana 179 (2015): 77-102. http://dx.doi.org/10.11144/ javeriana.tx65-179.tpps
Theory and Praxis of a Saving and Healing Pastoral

Aвstract: It tries to approach Pastoral Psychology from Isidor Baumgartner's proposal. Based on that discipline, it develops a theoretical framework, and adopts Baumgartner's main ideas and his method. The text ends with the appropriation of the author's thought, reassuming two strong topics of his approach: the saving power that arises from bringing together personal history and the Lord's history, and the ability of symbols to transform spiritual experience.

KeY words: Pastoral Psychology, praxis, Emaus, spiritual guidance, healing.

\section{Teoria e práxis de uma pastoral salvífica e curativa}

Resumo: Este artigo busca uma aproximação à psicologia pastoral a partir da proposta de Isidor Baumgartner. Inicia com uma breve história da mesma para desenvolver um quadro teórico, e faz uma opção pelo autor de referência descrevendo as ideias principais de seu pensamento e seu método. O texto culmina com a apropriação do pensamento de Baumgartner, retomando dois pontos fortes de sua abordagem: a força salvífica, que acrescenta o fato de unir a própria história à história do Senhor, e a capacidade dos símbolos para transformar a experiência espiritual.

Palavras-chave: Psicologia pastoral, práxis, Emaús, acompanhamento espiritual, cura.

\footnotetext{
* Artículo de reflexión escrito con base en la comunicación presentada en el I Seminario Internacional Permanente de Investigadores en Teología de las Prácticas, realizado en Santiago de Chile del 26 al 29 de marzo de 2012.

** Doctora en Teología, Pontificia Universidad Católica Argentina, Buenos Aires. Profesora de Teología espiritual y de Sacramento del matrimonio, Facultad de Teología, Pontificia Universidad Católica Argentina. Correo electrónico: marcela.mazzini@gmail.com
} 


\section{Introducción: el valor de un manual}

Posiblemente, llame la atención el hecho de dedicar un artículo de estudio a un libro que no es de un místico, de un santo o de un teólogo mundialmente renombrado. Si bien Isidor Baumgartner es un autor de referencia en psicología pastoral ${ }^{1}$, no entra en ninguna de las antedichas categorías. Sin embargo, considero que su aporte a esta disciplina, hecho por medio de un manual, tiene virtudes que deben ser consideradas, tanto en orden a un aprovechamiento de su pensamiento, como para inspirar otros desarrollos que pudieran hacerse sobre el tema.

Podemos decir entonces que el propósito de nuestro estudio es humilde desde un punto de vista y ambicioso desde otro. Es humilde, en cuanto intenta presentar la obra de un autor. Es ambicioso, al pensar que puede inspirar la reflexión de otras personas en el campo de la psicología pastoral.

Presentemos entonces brevemente al autor y la obra de referencia, para introducirnos luego en algunas cuestiones específicas.

Isidor Baumgartner nació en 1946, es laico, casado y padre de tres hijos. Se desempeña como catedrático de Teología y profesor de Psicología pastoral desde 1975, en Passau y Wien. Compagina estas actividades participando activamente en el campo de la orientación pastoral y en la preparación de cursos de formación y posformación. ${ }^{2}$ Se ha especializado en la formación para la orientación pastoral (en nuestro ámbito llamaríamos a esta actividad "acompañamiento" o "dirección espiritual”) y en la organización de cursos de Psicología pastoral como parte del currículo de estudios teológicos o de posgrado. ${ }^{3}$

En su libro Psicología pastoral. Introducción a la praxis de la pastoral curativa ${ }^{4}$ Baumgartner vuelca sus conocimientos y su experiencia, con el interés de establecer un nexo entre psicología y teología. Escribe teniendo como premisa la constatación

\footnotetext{
${ }^{1}$ Este autor es más conocido y citado en medios sajones que latinos, y también es más referenciado en medios reformados que católicos, aun cuando él un autor católico.

${ }^{2}$ Mazzini, "El acompañamiento espiritual como práctica eclesial. Apuntes a partir del pensamiento de H-J. Gagey, D. Tracy e I. Baumgartner”.

${ }^{3}$ Esta actividad la desarrolló particularmente en las facultades de teología de Passau y Wien. Si bien este autor es católico, mantiene un fluido intercambio con otras confesiones cristianas, en especial con la Iglesia Luterana.

${ }^{4}$ El libro consta de 757 páginas. La edición original, en alemán, apareció en Dusseldorf, en 1990, con el título Pastoral Psychologie. Einfürung in die Praxis Heilender Seelsorge. En español hay una reedición de Desclée de Brouwer (la misma que lo editó originalmente), de 2009. Con posterioridad a la edición de 1990 de Pastoral Psychologie, Baumgartner escribió colaboraciones en varias obras colectivas y diversos artículos en publicaciones, todos sobre psicología pastoral. Ha sido traducido en varios idiomas.
} 
del sufrimiento psíquico que experimentan miles de personas, entre ellas, numerosos creyentes. Según Baumgartner, para la Iglesia, el desafío consiste en acompañar a los seres humanos en estos difíciles trances vitales. Para ello, considera -como medio más apto-seguir la metodología aplicada por el mismo Jesucristo en el camino de Emaús (Lc 24,13-35): contemplar la historia personal a la luz de la historia de la relación de Dios con el género humano.

En el prefacio de su obra, Baumgartner hace un señalamiento que parece guiar su reflexión: no puede haber ningún discurso de sanación sin curación efectiva ${ }^{5}$, a ejemplo de Jesús, quien al hablar de curación, sanaba efectivamente. ${ }^{6}$ Hoy la psicología y las ciencias de la salud nos proveen de cantidad de recursos para acompañar e implementar el cuidado pastoral, recursos que debemos usar.

En su libro, Baumgartner se dirige a todo aquel interesado en el tema, pero particularmente a quienes se dedican al asesoramiento pastoral y a estudiantes de los últimos ańos de las carreras teológicas, sean aspirantes al sacerdocio o laicos. El texto, de una extensión considerable, consta de un prólogo y ocho partes. La estructuración de la obra obedece al esquema de pastoral salvífica y curativa que -según su autorrealiza Jesús en el camino de Emaús.

En este estudio, Baumgartner da mucha importancia a la praxis, de hecho, escribe el libro después de ejercer por quince años como orientador y formador en el ámbito de la psicología pastoral. Es característica de esta disciplina promover una mejor praxis y aprovechar la praxis para lograr una teoría mejor. De esta manera, intenta adentrarse en "una tierra de nadie, en ese lugar entre la teología y la psicología, la pastoral y la psicoterapia."” Pretende así entregarnos, no un estudio completo y acabado, sino un cuaderno de viaje con descripciones que permitan introducirse en este paisaje nuevo, que es la psicología pastoral. ${ }^{8}$ Veamos ahora el desarrollo disciplinar tal como lo narra Baumgartner.

\section{Corta historia y largo pasado de la psicología pastoral}

La primera tarea que emprende el profesor Baumgartner es ubicarnos en la historia de la disciplina. Tal como sucede con la psicología y con la teología práctica en general’

\footnotetext{
${ }^{5}$ Baumgartner, Psicología pastoral, 8.

${ }^{6}$ Esto mismo afirma Dorsaz, en su libro Psico-espiritualidad. La alianza que cura, 229-232.

${ }^{7}$ Baumgartner, Psicología pastoral, 11.

${ }^{8}$ Ibid., 11.

${ }^{9}$ Así lo vimos en el trabajo de Gagey, Notas acerca del estatuto de la teología práctica, 1.
} 
la psicología pastoral tiene una corta historia y un largo pasado. No es mi intención comentar aquí su historia completa, sino señalar algunas instancias para seguir, junto con el autor, el devenir de la disciplina, en orden a comprender mejor su planteamiento epistemológico.

Los textos bíblicos constituyen el primer antecedente, ya que se encuentran plenos de afirmaciones que se podrían calificar como de honda penetración psicológica. Desde el comienzo de la reflexión cristiana, se ha marcado un esfuerzo por abordar las molestias físicas y psíquicas desde una perspectiva creyente y desarrollar una teología terapéutica. Sin embargo, siempre ha habido resistencias y escollos en este camino de reflexión. ${ }^{10}$

Un segundo paso, en este camino, lo tenemos en la sabiduría vital y las acciones de los santos padres (ASPP). En efecto, los padres espirituales de los antiguos monasterios, quienes se consideraban médicos del alma y terapeutas ${ }^{11}$, seguían la inspiración de Christus-medicus. Como guías de almas se esforzaban en el trabajo de la diakrisis (diferenciación, discernimiento), y en una profunda percepción de los logismoi (pensamientos, mociones interiores), en especial, de los pensamientos oscuros o perturbadores. ${ }^{12}$ En esa línea de sabiduría para la guía de almas se encuentran los Stromata de Clemente de Alejandría (215), las obras de Orígenes (siglos II-III) y de Basilio (siglo IV).

En la Iglesia Occidental encontramos las descripciones de Prudencio (siglo IV) sobre la fuerza de luz y sombra que hay en el ser humano, las descripciones del entendimiento perceptivo de Gregorio Nacianceno (siglo IV) y las agudas observaciones que aparecen en la Regla pastoral de Gregorio Magno (siglo VI). Por fin, están las Confesiones de Agustín (siglos IV-V).

Al comienzo de la Modernidad encontramos escritos de consejo pastoral individual en la Devotio moderna y en los escritos de Ignacio de Loyola (1491-1556) con su discreción de espíritus. Un siglo más tarde, leemos las indicaciones de Francisco de Sales (1567-1622), quien manifiesta una fina percepción en el cuidado de almas. En los siglos siguientes se insistió en la formación de los directores espirituales y de los pastores de almas; una obra de referencia es Pastor bonus (1690), de Johannes Opstraets.

\footnotetext{
${ }^{10}$ Ver a Sanchez, "Antropología cristiana y psicología. Perspectivas para la integración”, 29-54.

${ }^{11} \mathrm{Al}$ respecto pueden consultarse las interesantes reflexiones de Leloup y Boff, en Terapeutas del desierto. De Filón de Alejandría y Francisco de Asís a Graf Dürckheim. Particularmente, la fenomenología de los itinerarios espirituales, que se describe en el comienzo del libro (18-27).

${ }^{12}$ Especial atención merece el método antirrético de Evagrio Póntico, para discernir "logismoi" o mociones interiores. Una exposición del método de evagriano y su influencia en los padres del desierto puede encontrarse en Grün, La sabiduría de los padres del desierto, El cielo comienza en ti, 63-100.
} 
En el recorrido de la historia (o prehistoria) de la psicología pastoral, Baumgartner señala algunas referencias importantes que permiten ver cómo el tema del acompańamiento espiritual, la conversación espiritual y el discernimiento han estado siempre presentes en la historia de la Iglesia. ${ }^{13}$ Nombra específicamente a Johan Michael Sailer (1751-1832), con sus reglas para la orientación en el cuidado de almas, de quien daba clases sobre la rectitud de la intención en el cuidado de almas, etc.

Otro momento importante en la historia de la psicología pastoral se encuentra, hacia la mitad del siglo XVIII, con la Ilustración y su forma de pensar empírico-deductiva. En esa etapa se introduce, en el cuidado pastoral, el concepto de "medicina pastoral”, que es contemporáneo a la primera cátedra de teología pastoral en Viena, en 1774. Como resultado de esa experiencia se publica la Teología pastoral de F. Ch. Pittrof, en 1783.

De la misma época es F.C. Mezler, a quien se reconoce como el fundador de la medicina pastoral, al hablar por primera vez de cuestiones puramente psicológicas en el cuidado de almas.

Durante los siglos XVII y XVIII, la psicología pastoral sigue la forma de medicina pastoral, en cuanto la psicología misma aún no es una disciplina enteramente distinta de la psiquiatría y de la medicina general.

En el siglo XIX, cuando la psicología comienza a establecerse con estatuto epistemológico propio, puede comenzar a ser pensada en relación con la teología práctica o pastoral. Es entonces cuando la medicina pastoral es reemplazada por la psicología pastoral, motivo por el cual podríamos decir que aquí comienza el desarrollo propiamente dicho de la psicología pastoral como ciencia, tal como la conocemos hoy.

Un autor de referencia es Anton Boisen. Nacido en 1876, parte -como Freud- de la teoría conflictiva como génesis de la experiencia religiosa, para arribar a conclusiones científicas completamente diferentes. ${ }^{14}$ Descubre elementos comunes en la psicosis y en la conversión, ya que ambas surgen de conflictos interiores y desarmonías, acompañados por una clara comprensión de las lealtades últimas y posibilidades inalcanzables. Para Boisen, la religión ofrece una posibilidad de curación del conflicto,

\footnotetext{
${ }^{13}$ Ver el desarrollo y algunos detalles en Baumgartner, Psicología pastoral, 36-38.

${ }^{14}$ Boisen padeció una enfermedad mental de la cual se recuperó. Fue precisamente en su experiencia como enfermo mental que descubrió su vocación como capellán de tiempo completo en un hospital para enfermos mentales. Estaba interesado en el significado de las psicosis y dedicó mucho tiempo a la investigación de las implicaciones religiosas de las experiencias psicóticas. Al partir de sus propias vivencias como enfermo mental y del estudio de otros casos, arribó a la formulación de su hipótesis: existe una relación significativa entre la enfermedad mental aguda de tipo funcional y la conversión religiosa, como la de San Pablo.
} 
trabajando mediante las crisis para conducir a la responsabilidad ética productora de mayores lealtades. ${ }^{15}$

En este desarrollo histórico, solo hay un verdadero diálogo entre psicología y teología hasta después del Vaticano II. Ello se debe a la postura agnóstica que adopta la misma psicología, en la mayoría de sus expresiones, y a la mirada algo prejuiciosa de la teología sobre la psicología durante largo tiempo. El Concilio marca un cambio muy importante en la postura de la Iglesia, y en este sentido, el decreto Optatam totius contiene, en particular, señalamientos muy importantes (OT 11, 19-20).

Solo después del Concilio se genera una mutua apertura que facilita el intercambio y que contribuye de manera notable al desarrollo de la psicología pastoral. La apertura conciliar se reforzó en la Ratio fundamentalis institutionis sacerdotalis, de 1970, cuando se recomienda expresamente la formación psicológica para los pastores y directores espirituales.

En el posconcilio, un hito en el desarrollo del tema es la fundación, en Alemania, en 1972, de la Sociedad Alemana para la Psicología Pastoral. Los teólogos evangélicos fueron muy activos en el tema de la formación para el consejo espiritual, en el cual se incluyeron los hallazgos de las investigaciones empíricas y psicoanalíticas.

Seward Hiltner ${ }^{16}$-discípulo de A. Boisen- es el iniciador del Pastoral Counseling, en el que se aplicaba la psicoterapia por la conversación de Carl Rogers ${ }^{17}$ al consejo pastoral, dejando abierto un amplio campo de intercambio con la psicología humanista. En esta línea, hay que nombrar la carrera de Counseling espiritual que se dicta desde hace algunos años en el Teresianum, en Roma, bajo la dirección de Luis Jorge Gonzalez, O.C.D. ${ }^{18}$

${ }^{15}$ La obra principal de Boisen es Exploration of the Inner World: A Study of Mental Disorder and Religious Experience. Allí, con distancia temporal de su propia recuperación, se estudia a sí mismo como un caso.

${ }^{16}$ Hiltner, Pastoral Counseling.

${ }^{17}$ Su teoría puede conocerse por medio de estas dos obras fundamentales: Rogers, Psicoterapia centrada en el cliente; Idem, El proceso de convertirse en persona. En los ańos 80, hubo un esfuerzo importante por aprovechar, para el diálogo de acompañamiento espiritual, el coloquio de Carl Rogers. Uno de los intentos más exitosos fue el método de Carkhuff, divulgado por una obra de Bruno Giordani que tuvo gran repercusión: Encuentro de ayuda espiritual. Adaptación del método de R.R. Carkhuff. En este libro se desarrolla, paso a paso, el modo de llevar adelante la conversación de reflejo al estilo rogeriano, pero adaptada al coloquio espiritual. Todavía se la utiliza en los ámbitos para la formación en counseling espiritual o pastoral.

${ }^{18}$ Esta interesante propuesta se orienta sobre todo al acompańamiento espiritual. Es de resaltar la notable producción bibliográfica que tiene sobre el tema el padre González. Dicha bibliografía puede verse en Luis Jorge González, www.luisjorgegonzalez.org.mx (consultado el 12 de octubre de 2014). 
Como pensamiento conclusivo de este recorrido histórico, podemos decir que la psicología pastoral quiere rescatar la sabiduría de vida expresada en la síntesis que tenían antiguos escritos cristianos, como la Didajé y la Didaskalia. Vida y fe deben reconciliarse, ya que -a lo largo de la historia- el cuidado de almas se fue tornando de bíblico-curativo hacia ascético-metáfísico, y se fue llenando de normas que no alimentaban la vida de los fieles.

Hay que revertir este camino hacia el encuentro de la dimensión curativa de la fe. Hoy en día se busca el modo de llevar adelante un diálogo más amplio y profundo entre teología, psicología, espiritualidad y praxis pastoral. A dicho diálogo busca contribuir la psicología pastoral.

\section{El marco teórico de la psicología pastoral: cruces, coincidencias y divergencias}

Al estudiar el tema de la psicología pastoral encontramos que su ubicación epistemológica es algo discutida. Mientras autores como Baumgartner la ubican dentro de la teología, otros estudiosos piensan que es una disciplina de la psicología, o una disciplina de cruce entre teología y psicología.

Así, W. Demal ${ }^{19}$, considerado uno de los pioneros de la psicología pastoral contemporánea, define esta ciencia como auxiliar de la teología pastoral, especialmente en el campo de la cura de almas.

Por otra parte, la postura de la psicología pastoral como disciplina psicológica o de cruce disciplinar puede estar representada por M. Szentmártoni ${ }^{20}$, quien afirma que la psicología pastoral está interesada principalmente en el análisis de la acción pastoral, aunque también ha ampliado su interés hacia otras áreas, particularmente la dinámica de grupos y los problemas relacionados con la muerte y el dolor. Este autor piensa que, epistemológicamente, hasta el momento, la psicología pastoral no está definida unívocamente.

Szentmártoni afirma además que muchos libros que tratan temas relativos a la psicología pastoral toman el nombre de Pastoral Counseling ${ }^{21}$ sin terminarse de ver, según él, la diferencia entre el counseling y el counseling pastoral, o la especificidad de

\footnotetext{
${ }^{19}$ Demal, Praktische Pastoralpsychologie.

${ }^{20}$ M. Szentmártoni es jesuita y dicta la materia Psicología pastoral en la Facultad de Teología de la Pontificia Universidad Gregoriana. Los conceptos aquí vertidos están tomados de los apuntes del curso, en su edición de 1993. En la misma universidad dicta también diversos cursos de Teología pastoral. Su obra puede consultarse en Manual de psicología pastoral.
}

${ }^{21}$ Se está refiriendo especialmente a Clinebell, Basic Types of Pastoral Counseling. 
este último. Dice que se deben considerar las dificultades que acabamos de señalar, pero intentando determinar algunos aspectos con claridad: la psicología pastoral es psicología y no teología; es una psicología que trabaja sobre la acción pastoral; pero el agente de dicha acción o intervención pastoral es un sujeto pastoral y no un pastor-psicólogo.

Sobre la base de estas consideraciones, Szentmártoni ofrece su definición: "La psicología pastoral es una rama de la psicología que estudia los procesos psicológicos inherentes a las situaciones pastorales." ${ }^{22} \mathrm{Al}$ ser psicología, y por su estrecha relación con las situaciones pastorales, siempre debe considerarse como sector del saber interdisciplinar.

E. Heise ${ }^{23}$, en el contexto argentino, se inclina por ubicar a la psicología pastoral del lado de la psicología pero en diálogo con (incluso al servicio de) la teología. Se expresa de la siguiente manera respecto de la localización de la psicología pastoral:

La psicología pastoral es, dicho en términos generales, una psicología en intercambio científico con la teología. Es una disciplina de la psicología que, a su vez, atribuye a la teología. La psicología pastoral está al servicio del conocimiento de la fe; es una "psicología hermenéutica" dedicada a entender los textos sagrados y su relación con los seres humanos. Trabaja como ciencia histórica en el sentido de ver la relación entre la biografía individual y lo histórico-simbólico en sus manifestaciones. A la teología práctica aporta sus investigaciones sobre los procesos de comunicación y su dinámica intrapsíquica y sus conocimientos sobre los conflictos humanos. La psicología pastoral ayuda a entender mejor, por un lado, a las personas a las que el pastor -o cualquier cristiano con esta tarea- quiere hacer llegar el Evangelio, y por el otro lado, contribuye a una mejor autocomprensión del pastor mismo. De esta manera, contribuye también a la antropología religiosa. La psicología pastoral no es solamente una ciencia auxiliar de la poiménica sino es, "psicología para toda la praxis de la Iglesia". Ella da un aporte sui generis a la psicología en general. ${ }^{24}$

Se trata de una ciencia que aporta, que dice relación con la teología, que colabora en el trabajo teológico; una ciencia que ayuda a entender desde una función hermenéutica. Por otra parte -nos dice Heise-, hace su aporte a la psicología en general. Este panorama ubica a la psicología pastoral en el centro de un área o cruce interdisciplinar.

\footnotetext{
${ }^{22}$ Szentmártoni, Introducción a la teología pastoral, 12.

${ }^{23}$ Ekkehard Heise, teólogo luterano, actualmente enseña Teología práctica en el Isedet, en Buenos Aires. $\mathrm{Su}$ CV puede verse en Doctor Ekkehard Heise, pastor, http://www.ekkehard-heise.de (consultado el 11 de octubre de 2014).

${ }^{24}$ Heise, "Cura de almas, el rescate de un concepto tradicional", Poiménica, http://www.ekkehard-heise. de/html/poimenica.html (consultado el 11 de octubre de 2014).
} 
I. Baumgartner, en su manual Psicología pastoral, encuadra esta disciplina claramente dentro de la teología práctica y nos señala sus "cometidos":

A la psicología pastoral le corresponde la función de hacer accesible, para la teología práctica, los resultados de la investigación psicológica del diagnóstico, la profilaxis y la terapia, de manera que puedan ser fecundos para una "praxis de la Iglesia" adecuada al Evangelio y a las preguntas de los seres humanos. Esto significa que la psicología pastoral participa en la función fundamental de la práctica teológica, a saber, "optimizar", en el sentido del Evangelio, la praxis eclesial que realiza. ${ }^{25}$

Según Baumgartner, la función específica de la psicología pastoral sería hacer accesibles sus resultados a la teología. ${ }^{26}$ Algunos de sus objetivos podrían definirse así:

- No es una "psicología para teólogos", ya que en ese caso dejaría de ser una disciplina teológica.

- $\quad$ Debe concebirse como parte de la teología práctica. Aquí hay que desarrollar más de qué manera se entronca en dicha rama teológica y cómo es su diálogo con las otras disciplinas que forman parte también de la teología práctica. Se trata de un verdadero diálogo intra e interdisciplinar.

- La psicología pastoral debe intentar dar respuestas a los pastores comunitarios, a los psicólogos pastorales, a los teólogos y a los psicólogos clínicos en temas de asesoramiento pastoral.

- Para los consejeros comunitarios, la psicología pastoral podría hacer que vuelvan a formar parte de la teología todas esas experiencias de fe sobre crisis y curación que han quedado fuera del conocimiento de numerosos pastores, cristianos y comunidades, y que forman parte, sin embargo, de las entrevistas de acompañamiento espiritual. La psicología pastoral podría traer a la luz y sistematizar todo el conocimiento que los "enfermos" o que las personas en crisis pueden aportar a los "sanos" en una comunidad.

- La psicología pastoral debería ocuparse con mayor profundidad de las crisis de los seres humanos, con sus dinámicas específicas, y la ayuda diferenciada que debería ofrecerse a estas personas. Baumgartner señala que falta un mayor

\footnotetext{
${ }^{25}$ Baumgartner, Psicología pastoral, 49. Para un marco más amplio del tema, ver 12-53.

${ }^{26}$ Hay que registrar la dificultad terminológica que se establece con las denominaciones "teología pastoral" y "teología práctica". Si bien la expresión ha sufrido una evolución, en lo concreto hay que cerciorarse, en cada autor, si considera estas expresiones como equivalentes o no.
} 
estudio de estas situaciones y de las oportunidades para hacer la intervención. A esta exploración de las situaciones la llama "cairología pastoral-simbólica". ${ }^{7}$

- La psicología pastoral debe cerciorarse de sus metas como parte de la teología pastoral o práctica, y de la misma actividad pastoral; vale decir: que sea un modo de anunciar la Buena Nueva de Jesucristo, y en tanto teología, reflexionar sobre ella. Hasta ahora, la psicología pastoral se ha visto involucrada sobre todo en el asesoramiento, pero ella tiene una misión en el anuncio, la liturgia y el sentido comunitario que todavía no ha desarrollado suficientemente.

- La psicología pastoral debe capacitar a los pastores para comunicar en función de las personas, y esto es inseparable de la trayectoria de fe del pastor y del conocimiento y sanación de las propias heridas.

- La psicología pastoral debe optimizar su propia didáctica, conformada de teoría, práctica y supervisión de la experiencia.

- Dentro de la pastoral, la psicología pastoral tiene la misión de recordar que la pastoral es salvífica y curativa, teniendo la función crítica de actualizar el patrón dado por Jesús en su praxis de sanación.

Baumgartner trata de mostrar cuál es el objeto y finalidad de la disciplina. Señala que, como parte de la teología práctica, el objeto de la psicología pastoral debe ser la praxis eclesial en sentido amplio, es decir, de los procesos que suceden entre la Iglesia (como organización) y los cristianos (como espacio de influencia donde el mensaje eclesial tiene recepción). Desde esta perspectiva, tienen que estar al mismo tiempo presentes la praxis curativa de Jesús, para imitarla (criteriología) y la situación psicosocial concreta de los destinatarios de esa praxis, que dará la pauta de la oportunidad y forma del anuncio (cairiología).

En cuanto a su cometido, a la psicología pastoral corresponde la función de hacer accesible, para la teología práctica, los resultados de la investigación psicológica respecto del diagnóstico, la profilaxis y la terapia, de manera que puedan llegar a ser fecundos para una praxis eclesial que sea a la vez adecuada al Evangelio y a las preguntas de los seres humanos. A partir, entonces, del análisis de la praxis psicológicopastoral se deben revisar cuán adecuadas son las instancias de acompañamiento de las personas, de acuerdo con las crisis vitales y las circunstancias con las que ellas se enfrentan hoy en día.

La psicología pastoral se presenta así como el terreno natural de diálogo entre psicología y teología. Este diálogo se impone, de algún modo, por las actuales condiciones

\footnotetext{
${ }^{27}$ Baumgartner, Psicología pastoral, 21.
} 
de vida y por la conciencia contemporánea de la fe. Los creyentes espontáneamente se cuestionan acerca de las implicancias psicológicas de su fe y del rol de sus creencias en su estructura psíquica. La teología y la pastoral esperan de la psicología un profundo conocimiento sobre lo que mueve hoy a los seres humanos, y sobre cómo se plantean la pregunta sobre Dios.

El Concilio Vaticano II dio un fuerte argumento para este diálogo, al hablar sobre la autonomía de las realidades temporales y la búsqueda de la verdad, que nos lleva -por caminos convergentes- a Dios (GS 36). La reflexión conciliar nos invita, pues, a dejar de lado toda "reserva antimoderna" respecto de la psicología, y a abrirnos al diálogo frente a los diversos caminos con los que contamos para comprender la realidad creada por Dios.

Esta dimensión dialogante y crítica de la teología está de alguna manera presente en el axioma de la teología escolástica, según el cual "la gracia supone la naturaleza y la perfecciona". ${ }^{28}$ Por otra parte, la economía de la encarnación, en la que lo divino y humano se unen, está hablando de esta lógica de comunión y diálogo que debe existir entre los diversos abordajes del misterio del hombre.

Baumgartner señala aquí uno de sus conceptos claves: para el intercambio con la psicología, la teología debe realizar una capacitación simbólica $a^{29}$ sobre las diversas huellas de Dios en la realidad de la creación, reflejada mediante la psicología.

La psicología pastoral participa en algo de la función de la teología fundamental de ser una "teología de las aristas" o de frontera, en el sentido de que está en diálogo con las ciencias y confrontada continuamente con planteos y dilemas diversos, provenientes de otros ámbitos humanos y científicos.

Hay intentos incluso de un diálogo más intenso y comprometido, no exento de riesgos epistemológicos y hermenéuticos que intentan relacionar las actitudes de la terapia centrada en el cliente con las virtudes de la fe, la esperanza y la caridad; o los de $\mathrm{E}$ Drewermann ${ }^{30}$, quien intenta incorporar a la exégesis conceptos de psicología profunda $^{31}$, para hacer una lectura de los textos bíblicos desde esa mirada.

\footnotetext{
${ }^{28}$ Generalmente formulado así: "Gratiam supponit naturam et eam non destruit sed perficit."

${ }^{29}$ La dimensión simbólica de la fe, la fe como símbolo y los símbolos en la vida de fe, son conceptos análogos con los que Baumgartner trabaja continuamente.

${ }^{30}$ Baumgartner se refiere concretamente al texto de Drewermann sobre el Evangelio de Marcos, Das Markusevangelium.

${ }^{31}$ Sobre esta cuestión resulta interesante lo que dice Grün sobre los temas que trata el Evangelio y la psicología de Jung. Ver a Grün, Evangelio y psicología profunda, 17-26.
} 
Como decimos y -bien señala Baumgartner-, estas lecturas pueden tener riesgos de concordismo-, de traspaso indebido de conceptos de un sistema a otro, o de no acatar los respectivos estatutos epistemológicos, desdibujando así los contenidos de las disciplinas. Por ejemplo, es evidente que no se puede identificar sin más la noción teológica de pecado con el sentimiento de miedo, pero al tiempo, nadie puede negar la relación que existe entre ambos. Tales intentos de acercamiento y diálogo, aunque tengan sus dificultades e incluso sus errores, resultan siempre enriquecedores.

En definitiva, valgan estas referencias para señalar los diferentes modos de ubicar la psicología pastoral -ya dentro de la psicología, ya dentro de la teología- y para percibir, por esto mismo, sus posibilidades interdisciplinares.

\section{La propuesta de Baumgartner desde la Sagrada Escritura: itinerario pastoral en el camino de Emaús}

Vamos a detenernos ahora en la propuesta concreta de Baumgartner para una psicología pastoral que incorpore el servicio que las ciencias del hombre en su desarrollo contemporáneo pueden brindar a la pastoral. Expondremos el tema en dos pasos: primero veremos la lectura que hace Baumgartner del texto de Emaús, y luego examinaremos la propuesta que el autor ofrece a partir de dicha lectura.

\section{El texto de Emaús y la lectura simbólico-existencial de Baumgartner}

Baumgartner propone una interpretación simbólico-existencial a la vez que elementalteológica. ${ }^{32}$ Con esta expresión se refiere a una lectura de la Palabra que, por ser una cierta exégesis del texto -entendida como concreta aplicación de la hermenéutica-, no responde a los criterios clásicos de la exégesis histórico-crítica. ${ }^{33}$

\footnotetext{
32 Baumgartner, Psicología pastoral, 91-92.

${ }^{33}$ Baumgartner dice que en ninguna de las interpretaciones exegéticas de esta perícopa, que él ha consultado (Psicología pastoral, 91, Nota 1) se habla explícitamente de un esquema de pastoral o consejo espiritual en la historia de Emaús, ni de un prototipo de acompañamiento para las crisis vitales. Sin desentenderse de los resultados de los biblistas, se anima a dar un paso más a partir de los límites de una interpretación histórico-crítica. Como primer límite, señala la globalización de la perícopa, es decir, la tendencia a intentar explicar toda la historia de Emaús desde un tema de narración único y original, y en este sentido no se llegará muy lejos, dado que la mayor parte de las interpretaciones descubren por lo menos cuatro temas en la narración. Estos serían: el reconocimiento del Resucitado, la legitimación cristológica de la comida en la comunidad, la catequesis mesiánica y la catequesis eclesial (ibid., 109-118). ¿Cuál será entonces el más importante o el que dé eje al relato? Baumgartner señala que los motivos de narración extraídos tienen un carácter marcadamente didáctico-dogmático que las interpretaciones más clásicas no logran alcanzar, pero al que aluden de alguna manera. Todos los temas o motivos que aparecen en las exégesis
} 
Tal interpretación se acerca más a lo que podemos denominar lectio divina, lectura meditativa de la Palabra de Dios, con una apropiación existencial que trata de investigar acerca de las situaciones humanas en relación con la fe. No se le escapa a Baumgartner -y le interesa mucho- la dimensión exegética clásica del relato; de hecho cita fuentes y autores que hacen la exégesis en este sentido ${ }^{34}$, pero de manera deliberada no quiere abordar un análisis convencional del texto. Veamos los pasos que va dando este autor.

Lc 24, 13-35

"En el camino" (v. 13). Todo lo que hasta ese momento contaba en las vidas de estos caminantes aparece destruido. Se mezclan entonces la ira -contra ellos mismos, contra Jesús y contra la realidad en la que están inmersos- y la tristeza, porque su amigo y maestro ha muerto, y con él se ha desvanecido un proyecto de vida. Se abate sobre ellos un caos de sentimientos. Tener que volver a Emaús les resulta doloroso y regresivo. A la ira y la tristeza podríamos sumar el desengaño y la nostalgia por lo que no fue, por lo que no pudo ser.

No es nada difícil identificarse con estos peregrinos. Cualquier lector puede reconocer alguna o varias circunstancias de su vida en este relato. Es, por otra parte, un motivo clásico en la sabiduría popular: existen momentos en la vida en los que todo parece desmoronarse.

Hay otra verdad que recoge la historia de Emaús: toda vida humana es un camino que cada uno recorre como puede, con sus tramos gozosos, difíciles e incluso intransitables. El símbolo del camino, presente en diversas culturas, es asumido por la sabiduría popular a la que antes aludíamos y por las diversas religiones, desde la noción de itinerario interior o espiritual.

Como motivo cultural nos basta recordar el viaje de Ulises hasta Itaca, a partir del cual todo viaje tiene algo de odisea: el tema del peligro, la lucha, la purificación y los obstáculos que el héroe debe superar para llegar a la meta. Este sesgo está también presente en el relato de Emaús.

Se va develando que el sentido del viaje no es llegar a la meta geográfica sino viajar en sí, y que este viaje opera una transformación en la persona que viaja. Como el caso del peregrino de la Edad Media: viajaba penitencialmente y devotamente a los

de los textos pueden considerarse complementarios y nos dicen que en el texto hay un esquema pastoral para los caminos de la praxis de acompańamiento dentro del cuidado curativo espiritual.

${ }^{34}$ Ibid., 109-118. Allí están expuestos los temas narrativos de la historia de Emaús y la lectura del texto desde la exégesis histórico-crítica. 
lugares santos y volvía transformado. "Quien se pone en marcha tiene ya detrás de sí el primer paso importante para salir de la crisis. Estará abierto a aquello con lo que se encuentre, propio y ajeno." 35

"Se les acercó y caminó con ellos" (v. 15). La partida de los discípulos hacia Emaús es más una huida que un viaje premeditado. Con el camino vuelven los acontecimientos vividos, los recuerdos, el tratar de comprender. Baumgartner señala que ambos debieron sentirse agradecidos por la presencia del otro. Ese "otro" conoce lo sucedido y comparte los sentimientos, y de este modo la soledad se disipa, pero todavía no se ilumina con el sentido.

Aparece allí la imagen del Señor como acompañante desconocido, y esto constituye el centro de la Buena Noticia y algo hondo que se quiere transmitir: cuando la crisis se revela al protagonista y a los otros en toda su fuerza, cuando no aparece el sentido de lo que se está viviendo, aparece Dios, que se hace especialmente cercano en los momentos difíciles de la vida. Dios está aquí y es el Dios-con-nosotros: esta es la experiencia central del judeo-cristianismo. ${ }^{36}$ En medio del miedo y la situación sin salida, está Dios; especialmente allí está el Señor. Pablo puede dar un paso más. Jesús no solo está con nosotros, sino en nosotros: "Es Cristo que vive en mî" (Ga 2,20): no solo cerca, sino en nosotros, dentro de nuestro corazón.

"Pero sus ojos estaban cerrados para reconocerle" (v. 16). Quien no puede encontrar a Dios se ha vuelto ciego para las realidades que verdaderamente dan sentido a su vida, y no se comprende cabalmente a sí mismo; está truncado el acceso a la integridad y a la totalidad que todo ser humano anhela. Sin embargo, cuando el hombre se da por perdido a sí mismo es el momento en que más y mejor puede abrirse a Dios, y en ese momento se presenta el Resucitado como invitación-provocación a abrirse, aunque ellos solo lo perciban físicamente, como un compañero desconocido. Él está y espera el momento en el que ellos lo puedan percibir.

"Él les preguntó"(v. 17a). Este acompañante aparece y no permanece mudo, se incluye en aquello que ocupa y preocupa a estos jóvenes. No evade las preguntas candentes centrales: ¿Qué ha pasado? ¿Qué les ha pasado? ¿Cómo les afecta esto que les ha pasado? Todas conducen al núcleo, a que ellos se planteen la vida en toda su verdad.

\footnotetext{
${ }^{35}$ Ibid., 95.

${ }^{36}$ Ibid., 96.
} 
Las preguntas se dirigen al centro de la crisis: solo si ellos se animan a llegar al centro de lo que les duele, podrán percibir allí la fuerza de la resurrección.

El Señor los conduce allí, y ese es el arte de acompañar: ayudar a llegar a las preguntas cruciales, para percibir, desde allí, el anuncio de la resurrección. Jesús hace preguntas "mayeúticas" ${ }^{37}$ para hacer presente, repetir y elaborar lo que entristece. Se trata de elaborar lo que ha pasado con ellos en la herida; esto, para acercarse más a su mundo interno, al contacto con Dios, consigo mismos y con los hermanos.

"Se pararon con rostros tristes" (v. 17b). Semejantes preguntas solo pueden detener la marcha de los pies y de la conversación. Percatarse de la tristeza, no esquivarla, pertenece al trabajo del duelo. No se puede pasar por lo que duele, permaneciendo indiferente. Se siente la necesidad de detenerse, de comprender, de aclarar la situación. Frente a tal interrupción, el acompañante puede intervenir; sobre todo es deseable que permanezca junto al dolor de otro. Eso hace el Señor y nos enseña a hacerlo a nosotros.

"Pero nosotros esperábamos" (v. 21). Los caminantes señalan su decepción: ellos esperaban y se ha roto la esperanza que pusieron en Jesús de Nazaret. Eso que ellos esperaban ya no será: ni el mesías político, ni el mago religioso. El proceso interno que están llevando a cabo los conduce a un hecho central; después de haberse preguntado, de haberse detenido, percatándose del dolor, empiezan a vislumbrar que los caminos de Dios son más anchos y profundos: mientras se miden las cosas de Dios con criterios finitos y humanos no están sobre la pista del camino verdadero.

Ellos comienzan a percibir que nuestra esperanza engaña si la dirigimos a lo temporal y a lo mortal. El corazón no puede aferrarse a lo que muere y pertenece a lo terrestre: "No busquen entre los muertos al que está vivo" (Lc 24,5) es lo que escuchan las mujeres en el sepulcro vacío. El estudio de las verdaderas esperanzas del ser humano puede darse especialmente en la confrontación con la Sagrada Escritura; allí se nos dice lo que le cabe esperar al hombre.

“No debia el Mesias padecer todo esto?” (v. 26). El Resucitado está diciendo: Dios está junto al hombre cuando padece su crisis radical. Dios está tan inconcebiblemente cerca, que llega con nosotros al sufrimiento y a la muerte, y en esos abismos lo encontramos cuando ya no hay nada ni nadie. En el fondo, lo que se dirime o se conversa es: ¿̨or qué sufrir? ¿Cómo puede Dios consentir que el ser humano sufra?

\footnotetext{
${ }^{37}$ Sobre la mayeútica de Jesús como obstetricia espiritual, ver a Guenther, "Midwufe to the Soul", 81-108. Allí hay un hermoso paralelo entre el parto y el proceso que se da en el acompañamiento espiritual.
} 
El relato de Emaús no contesta tales preguntas, pero dice que nuestro sufrimiento es el suyo, que en la cruz se encuentran Dios y el hombre. Lo que les inquieta a ellos es precisamente el sufrimiento del Mesías. Este sufrimiento y muerte han desbaratado sus planes y los conducen de vuelta a Emaús.

En la interpretación que el Resucitado hace de la Escritura tiene lugar buena parte de la curación de sus heridas, en la que ellos van arribando a una nueva comprensión de lo que les ha sucedido y de la vida en general.

"Lo referente a él en todas las Escrituras" (v. 27). Jesús va haciendo una exégesis de la cual ellos tienen una necesidad profunda: les muestra el hilo conductor que atraviesa sus historias y las une a la del Resucitado. Esto les indica también la dirección de futuro, el sentido que puede tener su historia, la razón de lo sucedido y también de lo que sucederá. Mientras reflexionan sobre el sentido de sus vidas y lo unen a las historias de la Biblia, se acercan a un nuevo proyecto vital, verdadero y auténtico. Acción curativa de Dios para los seres humanos no solo es un pasado de héroes, sino lo que tiene lugar ahora, en el "hoy" de Dios. Cuando se habla del Mesías y de su destino, jél está con ellos!

Baumgartner sostiene un punto importante: la fuerza curativa de las historias narradas, en especial, las historias bíblicas. ${ }^{38}$ Lo narrado tiene fuerza salvífica; al narrarlo, se vuelve vivo y vivificante, fundamentalmente porque en las historias de la Biblia se cuenta a los seres humanos la cercanía de Dios, y esta cercanía se hace presente cuando nos entregamos a tales historias y dejamos que sean salvadoras para nosotros.

"Él partió el pan...y ellos lo reconocieron" (v. 30ss.). La certeza más profunda de que Dios está aquí se experimenta cuando se está convencido de haber dicho todo lo que hay que decir. Cuando los discípulos hacen el gesto comunitario y litúrgico de comer juntos, se hace evidente que Jesús está allí, con ellos. No solo han caminado junto al Resucitado, sino que han avanzado hacia él, hacia su lógica y su plan de salvación. La comida se convierte así en la fiesta de la cercanía de Dios, y se hace evidente lo que Dios quiere ser para los seres humanos.

"Yen el mismo momento partieron..." (v. 33). El objetivo de la marcha de Emaús no es la reunión en sí misma sino la nueva partida; lo que ellos vivieron como viaje regresivo

\footnotetext{
${ }^{38}$ A esto se refiere de manera muy hermosa Mercedes Navarro en el capítulo "Narrando", de su libro Siete palabras de Mercedes Navarro, 31-52. Es también un tema que ha estudiado Michael Schneider en Teología como biografía.
} 
es un nuevo comienzo, en el que parten nuevamente, pero ya no sumidos en la tristeza sino apurados por la alegría. Nos dicen que a quien se le aparece el Señor no lo puede guardar para sí: que esto lo impulsa a hacer partícipe a otros, para que también los hermanos puedan transformarse por la presencia del Dios compañero. Baumgartner insiste en que las experiencias pascuales no son sucesos privados sino experiencias curativas de la fe que se transforman en sucesos comunitarios.

Ellos vuelven a Jerusalén, y con esa vuelta están marcando el reencuentro consigo mismos y con su historia. Ellos mismos han cambiado y eso lo transforma todo.

\section{La propuesta de Baumgartner a partir de su lectura de Emaús}

¿Qué consecuencias se desprenden de esta lectura para una psicología pastoral acorde a las necesidades de hoy? Según Baumgartner, el cuidado anímico debe superar la manera de trabajar que tienen con frecuencia la ciencias de la salud, las cuales -entusiasmadas por los avances científicos- pretenden curarlo todo, aplazando incluso los límites de la vejez y de la muerte.

La fe tampoco debería actuar así. No se trata de una fe que sana instantáneamente, ya que eso pondría al pastor en el lugar de Dios. La Escritura nos habla de otro estilo curativo propuesto por Jesús; la superación de la enfermedad es solo una fase de la curación cristiana, se logre o no el restablecimiento de la salud. Dios permanece del lado del enfermo, del pobre, del que sufre y ha tomado partido por ellos. ¿Qué pasaría, por el contrario, con los discapacitados permanentes, con los enfermos incurables?

Curado, en sentido cristiano, no será solo aquel que recupera la salud corporal -aunque esto no se deje de lado- sino aquel que logra la fuerza de ser humano en el hombre Jesucristo, vale decir, que comprende y realiza su finitud, en la amplitud de sus posibilidades, siguiendo el camino cristiano y transitando según este camino la enfermedad y la muerte.

Necesitados de Dios estamos todos, enfermos y sanos, en tanto seres finitos y limitados. Esta es la raíz y motivo por el cual Dios puede curarnos. Se trata de un proceso de sanación integral, en el que se comprenden lo físico, lo espiritual, lo psíquico, lo individual y social, lo sano y lo enfermo, lo fuerte y lo débil. Curación tiene que ver con salvación.

A Baumgartner le gusta referirse a la psicología pastoral con expresiones como "cuidado anímico" 39 -en sentido amplio-o "pastoral curativa” ${ }^{40}$, y esto implica ayudar

\footnotetext{
${ }^{39}$ Baumgartner, Psicología pastoral, 26.

${ }^{40}$ De hecho, la expresión está en el título de la primera parte del libro, que comprende cinco capítulos. Ibid., 33-88.
} 
a las personas aceptarse a sí mismas como seres finitos, con costados oscuros y pecados, pero amadas y aceptadas por Dios, pudiendo contar con su gracia. Esta experiencia se puede tener en una conversación de ayuda, en la escucha de la Palabra, al asistir a una bendición, o participar de la Misa o de cualquier otra celebración litúrgica. Todos ellos son acontecimientos en los que los seres humanos entran en contacto con el poder curativo de Dios.

La psicología pastoral en esta visión no apunta solo a las personas individuales capaces de ejercer este ministerio sino hacia una "comunidad sanadora", en la que muchas son las personas dispuestas a ayudar a soportar la carga de los demás. ${ }^{41}$ Están dentro de este ministerio:

- La capacidad para sanar (1Co 12,9): “...a otro, fe, en el mismo Espíritu; a otro, carisma de curaciones, en el único Espíritu” (en el contexto de 4-11).

- La capacidad para consolar (2Co 1,3-4): “ ¡Bendito sea el Dios y padre de nuestro señor Jesucristo, padre misericordioso y Dios de toda consolación, que nos consuela en toda tribulación nuestra para poder nosotros consolar a los que están en toda tribulación mediante el consuelo con que nosotros somos consolados por Dios!"

- Y la capacidad para aconsejar (Ef 4,11): "Él mismo dispuso que unos fueran apóstoles; otros, profetas; otros, evangelizadores; otros, pastores y maestros."

El procedimiento a seguir para esta descripción de la pastoral salvífica está señalado en la estructuración del libro:

- Primera parte: Psicología pastoral. Símbolo de una pastoral curativa. Delimita el marco de la exposición, aclara algunos conceptos en torno de la psicología pastoral y explica la metodología a utilizar.

- Segunda parte: Pastoral curativa. Una vía de Emaús. Señala el relato de los peregrinos de Emaús como historia estructurante del asesoramiento pastoral en sus diversos momentos.

- Tercera parte: "Ceguera" y "tristeza." (Crisis en las trayectorias vitales). Trata sobre las distintas formas que adoptan las crisis.

- Cuarta parte: "Entonces se les acercó Dios y caminó con ellos." (Criterios y crítica al acompañamiento desde el consejo espiritual, en las crisis vitales). La mirada se dirige a los acompañantes de las personas que atraviesan crisis. El autor examina las características personales y la idoneidad de los asesores espirituales.

\footnotetext{
${ }^{41}$ Esta misma idea, aunque con otro marco teórico, podemos encontrarla en Pagola, Acción pastoral para una nueva evangelización, 163-179.
} 
- Quinta parte: "Él les preguntó..." (Pastoral, consejo espiritual diacónico y curativo y psicoterapia). A propósito de la pregunta de Jesús camino a Emaús, Baumgartner expone el momento de la ayuda o la diaconía que supone el auxilio psicológico. Explica allí algunos principios generales de diversas teorías psicológicas; en especial, se concentra en la teoría psicoanalítica, en la terapia del comportamiento y en la psicoterapia por la conversación o counseling pastoral. Señala los aportes que estas escuelas hacen a la comprensión del acompañamiento espiritual.

- Sexta parte: "Descubrir el sentido de la Escritura..." (Palabra de Dios que salva). Está dedicada a ver cómo la historia del hombre se ilumina con la historia de la salvación, y a la vez, de qué manera la historia salvífica se verifica en cada historia particular. En el relato de la propia historia, como historia de salvación, el recuerdo tiene un lugar importante en la elaboración de lo vivido.

- Séptima parte: "Partir el pan..." (La fuerza salvifica de los simbolos de la fe). Baumgartner explica la relación existente entre los símbolos sagrados y los grandes conflictos humanos que pueden ser elaborados con la ayuda de estos símbolos.

- Octava parte: "Entonces se les abrieron los ojos... Le reconocieron... y regresaron a Jerusalén... (Sobre los objetivos de la pastoral salvifica). Esta última etapa del relato de Emaús sirve para trazar algunas conclusiones en las que se verifican los objetivos de la pastoral curativa: el encuentro consigo mismo, con los demás y con Dios.

Baumgartner adopta el modelo del relato de los peregrinos de Emaús (Lc 24, 13-35) como método de pastoral curativa. Por eso se animará a hablar del camino interno junto a la vía de Emaús. Los jóvenes que se encuentran con el Resucitado recorren, más que una distancia física, sobre todo, un itinerario interior que los lleva a redimir sus historias de vida a la luz de la historia salvífica de Cristo. La historia de Emaús capta la pregunta que aparece en la vida de cada ser humano: ¿Cómo puedo encontrar en las crisis y callejones sin salida de la vida el camino de la salvación? ¿Cómo puedo encontrarme precisamente allí con el Señor, de manera que él sea luz y salvación para mi vida?

\section{Valoración de la propuesta de Baumgartner}

Lo que a Baumgartner interesa describir es evidentemente un itinerario interior, espiritual, que es el itinerario de cada ser humano. Es una metáfora que no ha perdido su vigencia y una experiencia de la que se encuentran hambrientos y sedientos los hombres de hoy: una fe que se alimente de la experiencia, experiencia que permite 
"abrir los ojos", reconocerse a sí mismo, reconocer a los hermanos y a Jesús caminando junto a nosotros.

Desde mi punto de vista, este camino es una enorme posibilidad de evangelización que se abre a la Iglesia, una puerta para proponer una verdadera pastoral salvífica y curativa ${ }^{42}$, una oportunidad para que las personas entren de manera protagónica en contacto con el poder curativo de Dios.

Me parece muy acertado el hecho de que, para este proceso, Baumgartner propone cuatro pasos o instancias que son los que definimos con los nombres de las tradicionales instancias pastorales. En el relato de Emaús él nos muestra cómo, a la crisis y desengaño de los jóvenes, el Resucitado responde con koinonía (acercarse), diakonia (preguntar), matyria (interpretar las Escrituras) y liturgia (partir el pan). ${ }^{43}$

Hay muchos elementos para destacar en la exposición de este proceso pastoral y espiritual. Rescato dos que me parecen especialmente importantes: la importancia de unir la propia historia a la historia de salvación y el poder transformador de los símbolos.

\section{Unir la propia historia a la historia de la salvación}

En la sexta parte de su libro, Baumgartner se dedica a mostrar la fuerza salvífica de narrar historias y cómo estas historias se potencian y adquieren un sentido nuevoal unirlas con la historia divina. ${ }^{44}$ En efecto, nuestras heridas nos ponen en contacto con nuestro núcleo, con nuestra debilidad personal y nos dan la oportunidad de abrirnos a nuevas conceptualizaciones.

Allí el Evangelio puede entrar como historia salvadora a mi historia necesitada de salvación ${ }^{45}$, donde la primera ilumina la segunda y le da sentido, mostrando posibilidades desconocidas. Ambas historias -la de Dios y la del hombre- entran en relación, y las personas acompañadas tienen la oportunidad de ver su historia iluminada y resignificada, y de descubrir el Evangelio como historia salvífica. Será tarea de los acompañantes espirituales procurar que los acompañados encuentren su historia en la historia salvífica del Señor.

${ }^{42}$ El reverso de una pastoral curativa o sanante está descrito en el libro de Stamateas, Intoxicados por la $f e$. Si bien es un trabajo de divulgación, se ve el poder patológico de algunas deformaciones religiosas.

${ }^{43}$ Baumgartner, Psicología pastoral, 123. En el original este texto está en cursiva.

${ }^{44}$ Ibid., 625-658.

${ }^{45}$ Ver a Jalics, El acompañamiento espiritual en el Evangelio. 
Esto que expresa el autor de referencia he podido verlo recientemente en una investigación que estoy haciendo sobre prácticas de espiritualidad ${ }^{46}$ en un Hospice. ${ }^{47}$ $\mathrm{Al}$ conversar con voluntarios y profesionales de la salud y leer historias de huéspedes ${ }^{48}$, me di cuenta de que muchas veces el sentido de la propia historia o de la historia de un hermano aparece en la narrativa. ${ }^{49}$

En el Hospice, quien relata visualiza para sí y para su interlocutor el sentido de lo sucedido, por más doloroso que sea. Esto he podido escucharlo tanto respecto de lo acontecido (la historia con todas sus idas y vueltas), como de lo hecho (lo que hizo el huésped, lo que hicieron otros o ellos mismos): relatar ayuda a tomar conciencia de la profunda significación que tiene lo que se está haciendo.

He podido percibir que, al narrar, los voluntarios no sienten la necesitan justificar lo hecho ante otros o ante sí mismos; simplemente, al contar se reencuentran con un "llamado" y hay un reenamoramiento del camino escogido. Se percibe tanto en voluntarios como en profesionales de la salud un contento íntimo, profundo, de gran satisfacción por una comprensión existencial; comprensión que es simultáneamente de la propia vocación y del aporte que se hace a los demás y a Dios; una percepción de totalidad armoniosa.

La práctica del voluntariado en el Hospice, por ejemplo, le hace sentido al voluntario o voluntaria, y a su vez él o ella sienten que eso que están haciendo es útil y tiene sentido para los huéspedes.

El sentido de la narrativa se potencia cuando esa narrativa entra en la narrativa que es la Biblia. Esto se visualiza claramente en las despedidas que escriben los voluntarios al fallecer un huésped. Cuando esto ocurre, el voluntario que más lo ha tratado escribe una pequeña reseña de su paso por el Hospice y lo asocia a un texto

\footnotetext{
${ }^{46}$ Sobre el tema de prácticas de espiritualidad puede consultarse a Liebert, "Practice”, 496-514; también el trabajo realizado en dos centros de espiritualidad en Buenos Aires: Azcuy y Mazzini, "Sujetos, itinerarios y prácticas carismáticas. La espiritualidad en dos 'casas de irradiación' de Buenos Aires”, 117-156.

${ }^{47}$ Un Hospice es una casa de acogida para enfermos terminales; a quienes se alojan en ella no se los llama "pacientes", sino "huéspedes". Así se refuerza el sentido de hospitalidad que tiene la experiencia. El Hospice en cuestión es el Hospice "San Camilo", y está ubicado el Olivos, en la provincia de Buenos Aires, Argentina. Datos sobre el mismo pueden verse en su página web: www.hospicesancamilo.org.ar. En cuanto a la investigación, se trata de un plan de posdoctorado para profesores de la Universidad Católica Argentina, que forma parte de una investigación grupal de su Facultad de Teología, sobre prácticas de espiritualidad popular.

${ }^{48}$ Ver a Medylewski (comp.)-Hospice San Camilo, Haciendo el Hospice. Crónicas y Apuntes, El libro del Primer Año, 25-32; también ver Movimiento Hospice Argentina, "Historias de vida en los hospices", 61-95.

${ }^{49}$ Muy esclarecedor en este tema es el aporte de Grieu, “¿La Iglesia en la escuela de los creyentes más humildes? La importancia de los relatos de vida”, 355-387.
} 
bíblico. Estas notas de despedida, con la Palabra, son como un broche de oro para una existencia que termina. En la historia de quien ha partido vemos una historia de salvación, que con la puerta de la Palabra entra en la historia de la salvación. De este modo, la vida de quien se fue sigue hablando a los hermanos, personalmente y como comunidad; algunas veces, solo al concluir, puede percibirse un mensaje oculto en una trama de dolor y perplejidad.

Habitualmente, en estas narraciones se encuentra el sentido de la historia cuando se encuentra el amor: de los padres, de la familia, de Dios; pero es, sin duda, el amor de Dios el que opera como sintetizador y potenciador de sentido. Este amor salvador reorganiza las piezas de un rompecabezas vital, a menudo indescifrable desde otra óptica.

\section{El poder transformador de los símbolos}

Al hablar de la liturgia, Baumgartner afirma que, en nuestra vida de fe, es especialmente relevante redescubrir el lenguaje de los símbolos. ${ }^{50}$ Para esto será necesario, primero, que los acompañantes espirituales valoren el poder de los símbolos, su lenguaje y su gramática, su poder pedagógico y liberador. ${ }^{51}$ Es importante descubrir los símbolos que tienen relevancia en la vida del acompañado, ya que todo el lenguaje humano, todas las historias de vida, tienen de por sí una fuerte carga simbólica. El arte del acompañante es descubrir esos símbolos y conectarlos con los rituales y símbolos de la fe.

Por ejemplo, toda la simbólica de los procesos de duelo viene redefinida por nuestros ricos rituales de exequias. ${ }^{52} \mathrm{El}$ autor habla del "poder transformador y curativo de los símbolos litúrgicos, que claramente muestran una correlación con los conflictos fundamentales humanos y responden a ellos". ${ }^{33}$

La fuerza de los símbolos también la estoy percibiendo en mi investigación en el Hospice. Me di cuenta de que había que buscar el significado de las prácticas, desentrañando los símbolos.

Por ejemplo, en una de las paredes del jardín del Hospice hay una cruz formada por pequeños ladrillos sobresalientes; y cuando pregunté por esa formación me contaron que todos los años hacen una celebración de la luz, a la que convocan a los

\footnotetext{
${ }^{50}$ Baumgartner, Psicología pastoral, 669-725.

${ }^{51}$ Bernard y Lack, "Símbolos espirituales", 1780-1797.

${ }^{52}$ Este tema está tratado de manera muy iluminadora en el libro de Grün, El gozo de vivir. Rituales que sanan.

${ }^{53}$ Baumgartner, Psicología pastoral, 138.
} 
familiares y amigos de quienes han pasado por el Hospice y los invitan a colocar una pequeña vela sobre uno de esos ladrillos en honor al ser querido que partió y pasó por esa casa. Queda así formada una cruz luminosa. Dicha celebración es muy significativa no solo para familiares y amigos sino para los huéspedes, quienes saben que algún día brillarán "simbólicamente" en esa formación.

Los símbolos, aunque tengan un significado común, son personalísimos y únicos para cada persona. El ser humano simboliza, y al simbolizar elabora una experiencia a la vez que la transforma y la redime. ¿Qué está elaborando, simbolizando, orando y transformando esta persona o grupo a través de esta práctica? Esa práctica y ese símbolo son lo que hay que acompañar para comprender más a fondo a la persona y secundarla en su camino de sanación.

También los símbolos nos llevan a la noción de sentido. Por su práctica de espiritualidad, la persona o el grupo, o bien buscan conectar con el sentido, o bien encontrar un sentido que se presiente o se cree pero que no se encuentra. Esto es muy claro en el Hospice, donde -con estos símbolos y sus prácticas como condensación de espiritualidad vivida- se busca expresar el sentido, transitar el sentido, darle sentido a la muerte y al morir.

En síntesis, a partir de la escucha atenta y contemplativa de la historia de los hermanos pidámosle al Señor la gracia de ser como él: buenos compañeros de camino, capaces de permanecer junto a quien está triste, está solo o simplemente necesita encontrarse a sí mismo, contando su historia. ${ }^{54}$

\section{Bibliografía}

Azcuy, Virginia (coord.). Ciudad vivida. Prácticas de espiritualidad en Buenos Aires. Buenos Aires: Guadalupe, 2014.

Azcuy, Virginia, Carlos Schickendantz y Eduardo Silva (eds.). Teología de los signos de los tiempos latinoamericanos. Horizontes, criterios y métodos. Santiago de Chile: Ed. Universidad Alberto Hurtado, 2013.

Azcuy, Virginia y María Mazzini. "Sujetos, itinerarios y prácticas carismáticas. La espiritualidad en dos 'casas de irradiación' de Buenos Aires." En Ciudad vivida.

\footnotetext{
${ }^{54}$ Baumgartner, en Psicología pastoral, señala que es difícil permanecer junto a alguien que sufre, sin huir o dar soluciones (en particular, lo trata en el capítulo dedicado a analizar si los consejeros espirituales son apropiados para acercarse y acompańar (301ss.), y nos lo comunicó personalmente en la entrevista que tuvimos la doctora Azcuy y yo con él, en Passau, el 3 de noviembre de 2004.
} 
Prácticas de espiritualidad en Buenos Aires, coordinado por Virginia Ascuy, 117-156. Buenos Aires: Guadalupe, 2014.

Baumgartner, Isidor. Psicología pastoral. Introducción a la praxis de la pastoral curativa. Bilbao: Desclée de Brouwer, 1997.

Bernard, Charles y Roger Lack. "Símbolos espirituales." En Nuevo diccionario de espiritualidad, dirigido por Tullo Goffi, Stefano de Fiores, y Augusto Guerra, 1780-1797. Madrid: Paulinas, 1991.

Boisen, Anton. Exploration of the Inner World: A Study of Mental Disorder and Religious Experience. Pennsylvania: University of Pennsylvania Press, 1971.

Clinebell, Howard. Basic Types of Pastoral Counseling. Nashville: Abington Press, 1966.

De Mori, Geraldo Luiz. “El carácter práctico de la teología.” Teología y vida Vol. LI (2010): 501-519.

Demal, Willibald. Praktische Pastoralpsychologie. Wien: Herder Verlag, 1949.

Dorsaz, Gerard. Psico-espiritualidad. La alianza que cura. Burgos: Monte Carmelo, 2009.

Drewermann, Eugen. Das Markusevangelium. 2 vols. Olten und Freiburg: Walter, 1987-1988.

Gagey, Henri-Jêrome. Notas acerca del estatuto de la teología práctica. (Inédito).

Giordani, Bruno. Encuentro de ayuda espiritual. Adaptación del método de R.R. Carkhuff. Madrid: Atenas, 1985.

Grieu, Etienne. “¿La Iglesia en la escuela de los creyentes más humildes? La importancia de los relatos de vida." En Teología de los signos de los tiempos latinoamericanos. Horizontes, criterios y métodos, editado por Virginia Azcuy, Carlos Schickendantz y Eduardo Silva, 355-387. Santiago de Chile: Ed. Universidad Alberto Hurtado, 2013.

Grün, Anselm. El gozo de vivir. Rituales que sanan. Estella (Navarra): Verbo Divino, 1998.

. Evangelio y psicología profunda. Madrid: Narcea, 2003.

- La sabiduría de los padres del desierto. El cielo comienza en ti. Salamanca: Sígueme, 2000.

Guenther, Margaret. "Midwufe to the Soul." En Holy Listening. The Art of Spiritual Direction, por M. Guenther, 81-108. Cambridge (MA): Cowley Publications, 1992. 
Heise, Ekkehard. "Cura de almas, el rescate de un concepto tradicional." Poiménica, http://www.ekkehard-heise.de/html/poimenica.html (consultado el $11 \mathrm{de}$ octubre de 2014).

Hiltner, Seward. Pastoral Counseling. New York: Macmillan, 1949.

Holder, Arthur (ed.). The Blackwell Companion to Christian Spirituality. Oxford: Willey-Blackwell, 2011.

Marcelo Medylewski (comp.)-Hospice San Camilo. Haciendo el Hospice: crónicas y apuntes; el libro del primer año. Buenos Aires: Ed. Dunken, 2014.

Jalics, Francisco. El acompañamiento espiritual en el Evangelio. Buenos Aires: San Pablo, 2014.

Leloup, Jean-Yves y Leonardo Boff. Terapeutas del desierto. De Filón de Alejandría y Francisco de Asis a Graf Dürckheim. Santander: Sal Terrae, 1999.

Liebert, Elizabeth. "Practice." En The Blackwell Companion to Christian Spirituality, editado por Arthur Holder, 496-514. Oxford: Willey-Blackwell, 2011.

Mazzini, María Marcela. "El acompañamiento espiritual como práctica eclesial. Apuntes a partir del pensamiento de H-J. Gagey, D. Tracy e I. Baumgartner." Teología 111 (2013): 131-157.

Movimiento Hospice Argentina. Eres importante hasta el final. Disertaciones del Primer Encuentro del Movimiento Hospice en la Argentina, 2012. Buenos Aires: Claretianas, 2013.

. "Historias de vida en los hospices." En Eres importante hasta el final, editado por el Movimiento Hospice Argentina, 61-95. Buenos Aires: Claretianas, 2013.

Navarro Puerto, Mercedes. Siete palabras de Mercedes Navarro. Madrid: PPC, 1996.

Pagola, José Antonio. Acción pastoral para una nueva evangelización. Santander: Sal Terrae, 1991.

Rodríguez, María Isabel (dir.). Integrando la espiritualidad en la psicología. Burgos: Monte Carmelo, 2011.

Rogers, Carl. El proceso de convertirse en persona. Buenos Aires: Amorrortu, 1979. . Psicoterapia centrada en el cliente. Buenos Aires: Paidós, 1972.

Sanchez, José Ramón. "Antropología cristiana y psicología. Perspectivas para la integración." En Integrando la espiritualidad en la psicología, dirigido por María Isabel Rodríguez, 29-54. Burgos: Monte Carmelo, 2011. 
Schneider, Michael. Teología como biografía, Bilbao: Desclée de Brouwer, 2000.

Stamateas, Bernardo. Intoxicados por la fe. Buenos Aires: Grijalbo, 2010.

Szentmártoni, Mihály. Introducción a la teología pastoral. Estella (Navarra): Verbo Divino, 1994. . Manual de psicología pastoral. Salamanca: Sígueme, 2003. . Psicología de la experiencia de Dios. Bilbao: Mensajero, 2002. 